\title{
Severe hypoxemia without pulmonary infiltrates in systemic lupus erythematosus
}

\author{
Camilo Pena MD, Amputch Karukote MD, Jose Cuevas MD, Kenneth Nugent MD
}

\begin{abstract}
Fifty percent of systemic lupus erythematosus (SLE) patients have pulmonary disease which can involve the lung parenchyma, the pleural space, and pulmonary vessels. The article reviews the causes of severe hypoxemia in a SLE patient who had pulmonary hypertension patent foramen ovale, a history of recreational drugs use, asthma, and possible antiphospholipid syndrome who presented with acute dyspnea and severe hypoxemia. Her chest x-ray revealed cardiomegaly, increased central pulmonary vessels, decreased lung volumes but no infiltrates or effusions. Severe hypoxemia without pulmonary infiltrates in SLE patients is an unusual presentation; possible explanations include pulmonary emboli, severe pulmonary hypertension, and shrinking lung syndrome.
\end{abstract}

Key words: systemic lupus erythematosus, hypoxemia, patent foramen ovale, pulmonary hypertension, hypoxemia

\section{INTRODUCTION}

Fifty percent of patients with systemic lupus erythematosus (SLE) have pulmonary disease and could have several explanations for respiratory symptoms and hypoxemia. Our patient presented with acute dyspnea and severe hypoxemia but without pulmonary infiltrates on her chest imaging. Her past medical history included SLE, possible antiphospholipid syndrome, uncontrolled asthma, patent foramen ovale, pulmonary hypertension, and recreational drugs use. Severe hypoxemia without pulmonary infiltrates occurs infrequently in SLE patients; the possible causes are classified into three major groups for this review (Table).

Corresponding author: Camilo Pena MD

Contact Information: Camilo.pena@ttuhsc.edu DOI: 10.12746/swrccc2015.0312.158
CASE

A 31-year-old woman with SLE on mycophenolate mofetil, possible antiphospholipid syndrome on warfarin, uncontrolled asthma, patent foramen ovale, and pulmonary hypertension on sildenafil presented to the emergency department with sudden onset dyspnea and pleuritic chest pain. Her symptoms had developed during the previous 24 hours. She also had a persistent dry cough that was unchanged from her baseline. She denied having fever, purulent sputum, and hemoptysis. She gave a history of recreational drug used (cocaine, marihuana, ecstasy, methamphetamine). She also had a history of lupus nephritis class IV, but the details regarding her management were not available. In addition, her compliance with medication was suspect. Past evaluation included a cardiac catheterization 20 months prior to presentation with the following results: PA pressure $72 / 32$ $\mathrm{mmHg}$, mean PA pressure $46 \mathrm{mmHg}$, no response 
to nitric oxide, wedge pressure $12 \mathrm{mmHg}$, and normal coronary arteries. A transesophageal echocardiogram study done during this evaluation demonstrated right atrial enlargement, right ventricle enlargement, a moderate pericardial effusion, and large patent foramen ovale.

On presentation her blood pressure was $160 / 110 \mathrm{mmHg}$, heart rate 109 beats per minute, and respiratory rate 22 breaths per minute. Physical examination demonstrated diminished clear breath sounds bilaterally without crepitations. Her cardiovascular examination revealed tachycardia with trace pitting edema in her lower extremities.

Initial blood tests demonstrated no significant abnormalities; pertinent lab included hemoglobin 12.8 gms/dL, WBC $8 \mathrm{k} / \mu \mathrm{L}$, INR 1.01, and $\mathrm{Cr} 0.7 \mathrm{mg} / \mathrm{dL}$. The troponin $\mathrm{t}$ level was $0.25 \mathrm{ng} / \mathrm{ml}$ (nl: $0.01-0.03 \mathrm{ng} /$ $\mathrm{ml}$ ), and the BNP was $14,416 \mathrm{pg} / \mathrm{ml}(\mathrm{nl}:<124 \mathrm{pg} / \mathrm{ml})$ Her initial ABG revealed $\mathrm{pH} 7.48, \mathrm{PaCO}_{2} 25 \mathrm{mmHg}$, $\mathrm{PaO}_{2} 51 \mathrm{mmHg}$ on a $\mathrm{FiO}_{2} 100 \%$. A urine drug screen was not done. Her chest radiograph showed cardiomegaly, elevated diaphragms, and decreased lung volumes compared with previous chest radiographs

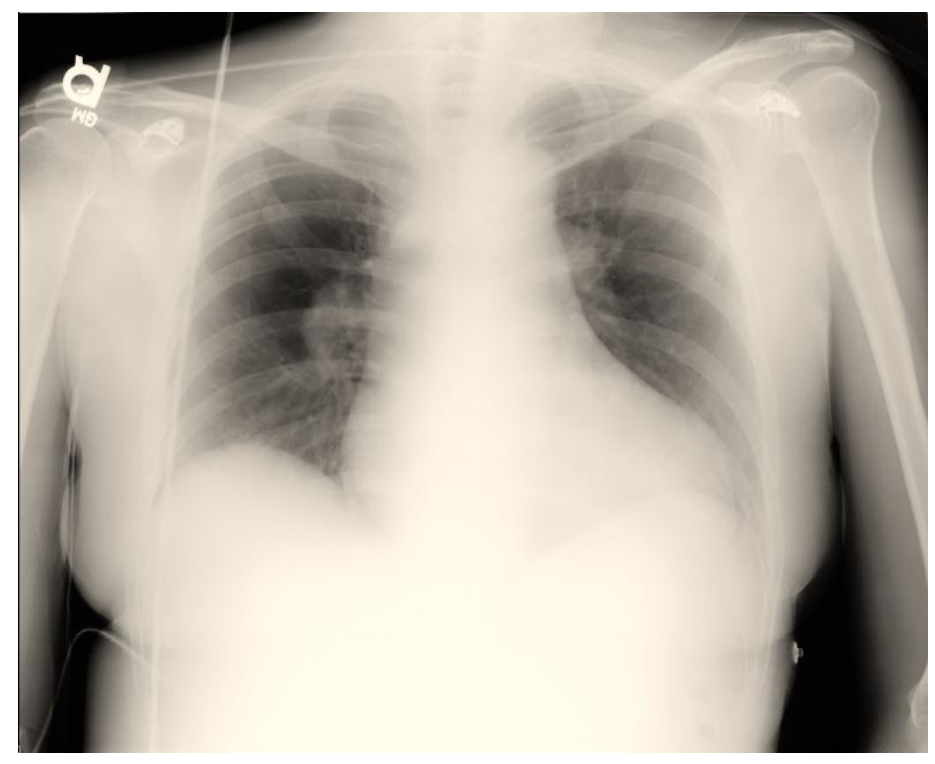

Figure1 : Portable A-P film on admission with cardiomegaly and clear lung fields. but no infiltrates, consolidation, or effusions. Spiral computed tomography with angiography of the chest revealed enlarged pulmonary arteries but no emboli or infiltrates. Transthoracic echocardiogram revealed a small chronic pericardial effusion without tamponade, an ejection fraction of 25\%- $29 \%$ (compared to $60 \% 20$ months prior to presentation), abnormal septal motion secondary to right ventricular volume/ pressure overload, global left ventricular hypokinesis, right ventricular systolic dysfunction, and severe pulmonary hypertension.

The patient was admitted directly to the medical ICU for acute respiratory failure. A few hours after admission, she became more distressed, and arterial blood gases showed severe metabolic acidosis with profound hypoxemia. The patient was sedated and intubated. Despite the use of multiple ventilator modes in an effort to raise her $\mathrm{PaO}_{2}$, the patient remained with hypoxemic $\left(\mathrm{SpO}_{2} 40-50 \%\right)$ and tachypneic $>30$ $/ \mathrm{min}$. She was received bag valve mask ventilation and ultimately developed pulseless electrical activity. After more than 40 minutes of ACLS, the patient was pronounced dead. Total treatment time in the ED and ICU was 8 hours and 26 minutes.

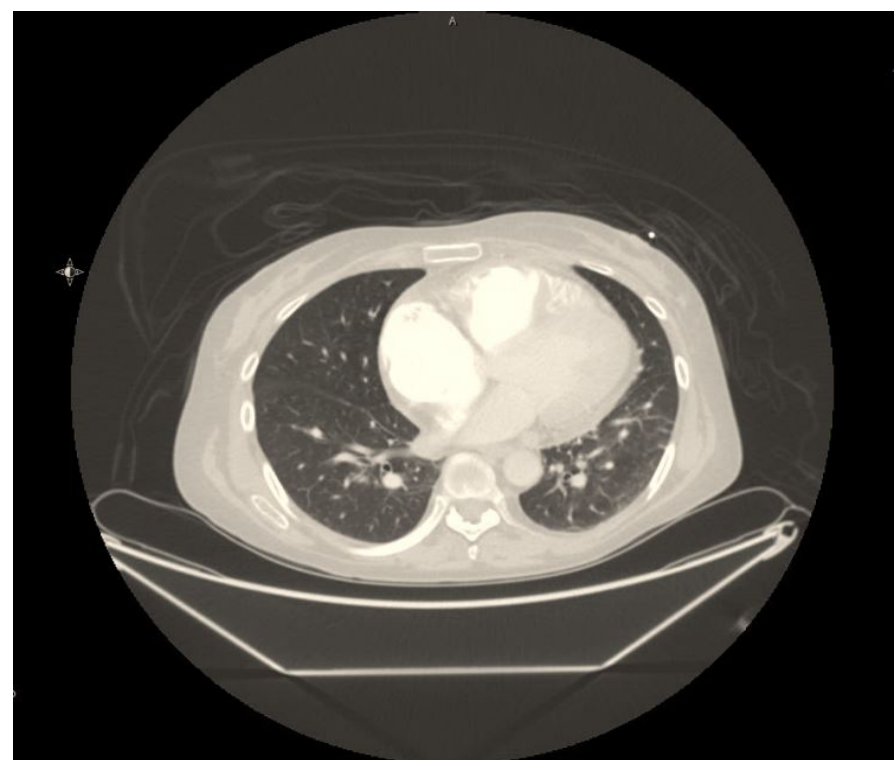

Figure 2 : Axial computed tomography of the chest with contrast with clear lung fields at lung bases. 


\section{Discussion}

A decreased $\mathrm{PaO}_{2}$ in an arterial blood gas is the definition of hypoxemia. The etiology of hypoxemia includes 5 major mechanisms: hypoventilation, low inspired $\mathrm{PO}_{2}$, right to left shunt, diffusion limitation, and ventilation/perfusion (V/Q) mismatch. Hypoventilation and low inspired $\mathrm{PO}_{2}$ are hypoxemic conditions with a normal $A$-a gradient which indicates normal alveolar-capillary gas exchange. Right to left shunt and V/Q mismatch both decrease the $\mathrm{PaO}_{2}$ and increase the A-a gradient.

Hypoxemia with a normal A-a gradient in this patient, i.e., hypoventilation and low inspired $\mathrm{PO}_{2}$, was unlikely to cause her symptoms because she presented with hyperventilation and was at a safe altitude. Moreover, her symptoms did not improve with oxygen supplementation on a mechanical ventilator which is the definitive treatment for hypoxemia with a normal A-a gradient.

Based on her past medical history and initial evaluation, possible explanations for her hypoxemia are listed in the Table below. SLE related lung dis- eases with infiltration were excluded by normal chest $\mathrm{x}$-ray and will not be discussed in this analysis.

\section{Right to left shunt (non-SLE related causes)}

Patent foramen ovale with Eisenmenger's syndrome

The foramen ovale is a hole in interatrial septum. In the fetal circulation, this foramen shunts oxygenated blood from placenta to the left atrium and systemic circulation. After birth, decreased pulmonary vascular resistance and increased left atrial pressure automatically close the foramen ovale. However, approximately $10-35 \%$ of the general population have a patent foramen ovale (PFO). ${ }^{2}$ PFOs shunt blood from left atrium to right atrium. Long standing shunting raises pulmonary vascular resistance and causes pulmonary hypertension $(\mathrm{PH})$. Severe $\mathrm{PH}$ associated with congenital heart disease is defined as Eisenmenger's syndrome. Without treatment, Eisenmenger's syndrome can convert a left-to-right shunt to right-to-left shunt. ${ }^{3}$ The exact prevalence of Eisenmenger's syndrome is uncertain; the reported prevalence is $1.1 \%-12.3 \%$ in patients with congenital heart disease. ${ }^{4}$ Eisenmenger's syndrome symptoms usu-

Table : Mechanisms for severe hypoxemia with elevated A-a gradients in a SLE patient without radiologic infiltration on chest $x$-ray

\begin{tabular}{|c|c|c|}
\hline \multirow[t]{2}{*}{ Right to left shunt } & SLE related causes & None \\
\hline & $\begin{array}{l}\text { Non-SLE related } \\
\text { causes }\end{array}$ & $\begin{array}{l}\text { Patent foramen ovale with or with- } \\
\text { out Eisenmenger's syndrome }\end{array}$ \\
\hline \multirow[t]{4}{*}{ V/Q mismatch } & \multirow[t]{3}{*}{ SLE related causes } & 1. Pulmonary arterial hypertension \\
\hline & & 2. Thromboembolic disease \\
\hline & & 3. Non-ischemic cardiomyopathy \\
\hline & $\begin{array}{l}\text { Non-SLE related } \\
\text { causes }\end{array}$ & $\begin{array}{l}\text { Severe asthma with respiratory } \\
\text { failure }\end{array}$ \\
\hline \multirow[t]{2}{*}{ Diffusion limitation } & SLE related causes & Shrinking lung syndrome \\
\hline & $\begin{array}{l}\text { Non-SLE related } \\
\text { causes }\end{array}$ & Recreational drugs use \\
\hline
\end{tabular}


ally develop in adolescents or young adults. The most common clinical features are chronic cyanosis and signs of right sided congestive heart failure. The initial investigation usually reveals secondary erythrocytosis. Treatment of $\mathrm{PH}$ associated with Eisenmenger's syndrome is controversial. Some studies recommend endothelin receptor antagonists, phosphodiesterase-5 inhibitors, and prostacyclins. The causes of death in Eisenmenger's syndrome patients include sudden cardiac death(29.5\%), right sided congestive heart failure(22.9\%), and severe hemoptysis(11.4\%). Godart reported 11 patients with severe hypoxemia secondary to right to left atrial shunting without $\mathrm{PH}^{6}$

A PFO with Eisenmenger's syndrome causes intracardiac right to left shunt that can lead to hypoxemia with an elevated A-a gradient. Her presentation with dyspnea and bilateral pitting edema can be explained by congestive heart failure from Eisenmenger's syndrome, even though there was no chronic cyanosis or secondary erythrocytosis associated with chronic hypoxemia. Presumably some acute event changed the magnitude of the right to left shunt to cause severe refractory hypoxemia.

\section{V/Q Mismatch (SLE related causes)}

Thromboembolic disease

Systemic lupus erythematosus is an autoimmune disease that can affect several organ systems. Fifty percent of SLE patients have pulmonary manifestations, including pulmonary embolism (PE). ${ }^{1} \mathrm{Ap}$ proximately $9 \%$ of SLE patients were diagnosed with a deep vein thrombosis (DVT) with or without PE in one study. ${ }^{7}$ Compared with the general population, SLE patients have a 19.7 fold increased risk of PE. Furthermore, the prevalence of PE increases in SLE patients with the antiphospholipid syndrome.

Typically, patients present with sudden onset dyspnea, hypoxemia, tachycardia, pleuritic chest pain, and fainting. Patients with massive PE can develop hemodynamic compromise leading to acute respiratory failure. The gold standard for diagnosis of PE is pulmonary angiography which is rarely performed in clinical practice due to its associated risks. However, the emergence of noninvasive studies, such as computed tomography with angiography (CTA), and V/Q scans also detect PE. SLE patients with possible antiphospholipid syndrome who have history of deep venous thrombosis should be treated with warfarin.

Our patient had an increased risk to develop PE due to her underlying SLE and possible antiphospholipid syndrome, and her presentation could be caused by PE. However, the basis for the diagnosis of antiphospholipid syndrome is unclear from her available medical records. She had had multiple pregnancies, and her lupus anticoagulant screen and cardiolipin screen were negative. Her spiral CTA of the pulmonary arteries did not demonstrate PE and decreased lung volumes are not readily explained by $P E$, at least at initial presentation. She did not have a therapeutic INR and small peripheral emboli could have caused decompensation.

\section{Pulmonary hypertension (PH)}

The definition of pulmonary hypertension requires an increased pulmonary arterial pressure $(P A P) \geq 25 \mathrm{mmHg}$ at rest or $>30 \mathrm{mmHg}$ on exercise with normal left sided filling pressures measured by right heart catheterization (RHC). ${ }^{10,11}$ Pulmonary arterial hypertension (PAH) is a subgroup of pulmonary hypertension that is caused by disease of pulmonary arterioles only. ${ }^{12}$ The exact prevalence of $\mathrm{PH}$ in SLE is unknown; several studies suggest it is approximately $1.8 \%-14 \%$. $^{13}$

The most common clinical features are gradually progressive dyspnea, chest pain, nonproductive cough, and edema. Some patients with $\mathrm{PH}$ present with presyncope, syncope, or fatigue. Physical examination reveals a loud $\mathrm{P} 2$ sound and signs of right ventricular enlargement; severe cases may present with sign of right ventricular failure. ${ }^{12,13}$

The definitive diagnosis requires $\mathrm{RHC} .^{10}$ However, other non-invasive studies are useful in this di- 
agnosis, including chest imaging, Doppler echocardiography, pulmonary function tests, and $V / Q$ scans. Chest imaging reveal enlargement of pulmonary arteries. Echocardiography is used to evaluate cardiac chambers and valves, and the systolic PAP can be measured by a transthoracic Doppler echocardiography. Pulmonary function test show decreased lung volumes and a decreased carbon monoxide diffusion capacity. V/Q scans may reveal normal perfusion or small peripheral non-segmental perfusion defects. ${ }^{9,11}$

The pathogenesis of $\mathrm{PH}$ associated with SLE remains unclear. Vasculitis and thrombosis, interstitial pulmonary fibrosis, and imbalances between vasoconstrictors and vasodilators could contribute to endothelial injury and vascular remodeling. Recent studies suggest that immunological and inflammatory processes are potential mechanisms for endothelial injury. IgG and complement have been found in pulmonary artery walls, and macrophages and lymphocytes have been found in plexiform lesions. ${ }^{12-15}$ In antiphospholipid syndrome, elevated circulating endothelin-1 could induce vasoconstriction which subsequently causes $\mathrm{PH}^{14}$

Treatment of $\mathrm{PH}$ includes oxygen supplementation, anticoagulants, and vasodilators. Several medications have been reported to be effective in the treatment of $\mathrm{PH}$ in SLE, including intravenous bolus cyclophosphamide with oral glucocorticoids ${ }^{16}$, phosphodiesterase 5 inhibiters ${ }^{17}$, endothelin antagonists, guanylate cyclase inhibiters, prostacyclin analogues. For severe $\mathrm{PH}$ associated with SLE, some studies recommend immunosuppressive therapy with pulmonary vasodilators. ${ }^{9}$

This patient had well documented $\mathrm{PH}$ and had been on sildenafil. Pulmonary hypertension could contribute to the hypoxemia in this patient. Patients with patient who discontinue sildenafil can decompensate. ${ }^{18}$ Increased PA pressure secondary to vasoconstriction and/or small emboli could increase right to left shunting and cause refractory hypoxemia.

Non-ischemic myocarditis
Non-ischemic cardiomyopathy is a rare cardiovascular manifestation of SLE. ${ }^{19}$ Non-ischemic cardiomyopathy includes myocarditis, cardiomyopathy, and heart failure. The definitive diagnosis requires endomyocardial biopsy, and the prevalence of this condition remains unclear. Postmortem studies report that $57 \%$ of patients with SLE have myocarditis. Six percent of patients with SLE had myocarditis by echocardiographic studies. ${ }^{20}$ Lupus cardiomyopathy can present without symptoms; some patients report non-exertional chest pain, dyspnea, palpitations, and signs of heart failure. ${ }^{21}$ Although echocardiography does not provide a definitive diagnosis, echocardiography can detect a decreased ejection fraction (as in this patient), increased chamber size, and global hypokinesis without coronary artery disease. Chest imaging reveals cardiomegaly. The recommended treatment is high dose intravenous methylprednisolone. ${ }^{21}$

In this patient, dyspnea with chest pain and a decreased EF could be explained by non-ischemic cardiomyopathy. She had had a significant change in cardiac function based on an echocardiograph done at presentation and had biventricular systolic dysfunction. A low cardiac output with a decreased mixed venous oxygen level would decrease her $\mathrm{PaO}_{2}$ independent of any change in gas exchange in the lungs.

\section{V/Q Mismatch (non SLE related causes) \\ Acute severe asthma with respiratory failure}

Acute severe asthma is defined as an acute asthmatic attack with severe respiratory symptom and abnormal gas exchange. Without aggressive treatment, acute severe asthma may lead to respiratory failure with $\mathrm{CO}_{2}$ retention. ${ }^{22}$ Short acting $\beta_{2}$ agonists, ipratropium bromide, and systemic corticosteroid should be given immediately. Without improvement, some studies recommend intravenous magnesium sulfate. $^{22,23}$ If symptoms persist, patients will require intubation and mechanical ventilation.

Airway obstruction from severe asthma can cause hypoxemia from V/Q mismatch with an elevated A-a gradient. Given her past medical his- 
tory of uncontrolled asthma, she might have had an acute severe asthma on this admission. Her clinical manifestation with acute dyspnea can be explained by an asthmatic attack since severe asthma attacks can present with the absence of breath sounds and wheezing (as in this case).

However, metabolic acidosis with decreased lung volumes is unlikely to be caused by acute severe asthma. At the beginning of asthmatic attacks patients should have respiratory alkalosis from hyperventilation which she had. When symptoms increase and respiratory muscles fatigue, patients can develop respiratory acidosis with $\mathrm{CO}_{2}$ retention. However, these patients should stabilize with mechanical ventilation, and chest $\mathrm{x}$-rays should show increased lung volumes. For these reasons, the hypoxemia in this patient is unlikely to be caused by acute severe asthma with respiratory failure.

\section{Unknown pathogenesis (SLE related causes) Shrinking lung syndrome}

The shrinking lung syndrome (SLS) is a rare pulmonary complication in SLE which can cause significant morbidity and mortality. SLS is characterized by dyspnea that cannot be explained by any other underlying pulmonary disorder, a restrictive pattern in pulmonary function tests, and reduced lung capacity with elevated diaphragms on x-rays. ${ }^{24}$ In the LUMINA cohort study, SLS was reported in $0.6 \%$ of SLE patients. ${ }^{19}$ Another study reported the prevalence of SLS in up to $6 \%$ in severe SLE patients who were refractory to therapy and undergoing hematopoietic stem cell transplantation (HSCT).

The most common respiratory symptoms associated with SLS are exertional dyspnea and pleuritic chest pain. ${ }^{26-28}$ Tachypnea with decreased chest wall expansion can be found on chest examination. Chest imaging reveals elevated hemidiaphragms and atelectasis without evidence of thromboembolism or pulmonary interstitial disease. Pulmonary function tests reveal a restrictive pattern with reduced lung volumes. ${ }^{29}$
The exact pathogenesis is still controversial; possible causes include microatelectasis due to surfactant deficiency, diaphragmatic myopathy, phrenic nerve neuropathy, and/or pleural adhesions or pain induced inactivation of diaphragm. ${ }^{24,30,31}$ Some recent studies suggest an association between anti-Ro/SSA with SLS.

Definitive treatment for SLS remains uncertain; several studies have suggested treatment with 20 $\mathrm{mg} /$ day to $1 \mathrm{mg} / \mathrm{kg} /$ day of oral prednisone after shortterm high dose intravenous methylprednisolone. ${ }^{33}$ Corticosteroids combined with immunosuppressive agents, such as azathioprine, cyclophosphamide, or methotrexate, are considered the second line treatment. ${ }^{29,31}$ Inhaled high-dose $\beta_{2}$ agonists and theophylline with or without corticosteroids possibly increase diaphragmatic strength. ${ }^{27}$ Furthermore, some case reports suggest that rituximab can improve dyspnea and pleuritic chest pain in refractory cases. However, there is no prospective randomized controlled trial on the efficacy of rituximab or other medication regimens in SLS due to its infrequent occurrence. ${ }^{34}$

Given her diagnosis of SLE and her presentation with the sudden onset dyspnea with pleuritic chest pain her hypoxemia could be caused by SLS. Moreover, the chest imaging showed decreased lung volumes without thromboembolism or interstitial lung disease. This explanation for hypoxemia in these patients could involve diffusion limitation if there is loss of vascular bed and increased cardiac output.

\section{Unknown pathogenesis (non SLE related causes)}

The patient used several recreational drugs, including marijuana, cocaine, ecstasy, amphetamine, and methamphetamine. These drugs can have complications involving the cardiovascular-respiratory system, including pneumonitis, hemorrhage, and increased pulmonary artery pressures, and could contribute to the hypoxemia in this patient. Given the limitations of history taking and the lack of a drug screen at presentation, the contribution of drugs to her presentation is uncertain. She did have prior positive 
tests for amphetamine.

Cocaine is sympathetic nervous system stimulant that can cause multiple organ system complications. Cocaine increases sympathetic activity and oxidative stress associated mitochondrial damage in cardiomyocytes and decreases myocardial oxygen supply from vasoconstriction; this drug has several cardiovascular complications, including myocardial infarction, arrhythmias, cardiomyopathy, and heart failure. ${ }^{35}$ In postmortem autopsies, $30 \%$ of decedents with cocaine-associated deaths had myocarditis. ${ }^{36}$ Moreover, there are many respiratory complications from cocaine, including asthma and acute exacerbations of COPD. ${ }^{37}$ The levamisole in cocaine may be a cause of pulmonary hypertension.

Ecstasy and methamphetamine are central nervous system stimulants which blocks neural catecholamine reuptake. In a retrospective study by Chin and colleagues, $28.9 \%$ of patients with idiopathic $\mathrm{PAH}$ had a history stimulant use, including amphetamine, methamphetamine, and cocaine. On other hand, only $3.8 \%$ of patients with a known cause of $\mathrm{PH}$ had a history of stimulant use. ${ }^{39}$ The suspected pathogenesis involves serotonin associated pulmonary vasoconstriction and proliferation of smooth muscle cell. Patients who have amphetamine induced $\mathrm{PAH}$ usually present with exertional dyspnea. ${ }^{40}$ The explanation for hypoxemia in these patients could involve diffusion limitation if the cross-sectional area of the pulmonary vascular bed is reduced and cardiac output is increased.

Although there is no definitive evidence of drug use on admission, recent drug use could have increased pulmonary artery pressures and increase the right to left shunting.

\section{Conclusion}

Severe hypoxemia without pulmonary infiltration in SLE is an unusual presentation. The article discusses a SLE patient who presented with sudden onset dyspnea and pleuritic chest pain. Chest imag- ing revealed decreased lung volume with elevated diaphragms and enlarged pulmonary arteries. There is no parenchymal disease or consolidation. Echocardiogram revealed a reduced EF. Based on her past medical history of SLE, possible antiphospholipid syndrome, uncontrolled asthma, patent foramen ovale, pulmonary hypertension, and history of recreational drugs and presenting clinical features, several mechanisms could cause hypoxemia in this patient. The causes of hypoxemia with elevated A-a gradients include right to left shunt, V/Q mismatch, and diffusion limitation (Table). Our analysis suggests that the best differential diagnosis in this patient includes patent foremen ovale with Eisenmenger's syndrome, SLE related pulmonary arterial hypertension, SLE related thromboembolic disease, SLE related shrinking lung syndrome, and recreational drug associated pulmonary vascular disease. Her sudden change in status probably reflected an acute increase in pulmonary artery pressure resulting in an increase in the right to left shunt and severe refractory untreatable hypoxemia. Possible precipitants include drugs such as amphetamine, pulmonary emboli, acute vasculitis, and/or withdrawal of sildenafil. Acute cardiac dysfunction with a low cardiac output would contribute to her hypoxemia.

\footnotetext{
Author Affiliation: Camilo Pena and Jose Cuevas are residents in Internal Medicine at Texas Tech University Health Sciences Center in Lubbock, TX. Amputch Karukote is a volunteer research assistant in the Department of Internal Medicine at TTUHSC in Lubbock, TX. Kenneth Nugent is a faculty member in the Pulmonary and Critical Care Division at TTUHSC in Lubbock, TX.

Received: 06/10/2015

Accepted: 10/09/2015

Reviewers: Victor Test MD, Anoop Nambiar MD

Published electronically: 10/15/2015

Conflict of Interest Disclosures: none
} 


\section{REFERENCES}

1. Pines A, Kaplinsky N, Olchovsky D, Rozenman J, Frankl O. Pleuro-pulmonary manifestations of systemic lupus erythematosus: clinical features of its subgroups. Prognostic and therapeutic implications. Chest 1985;88(1):129-135.

2. Shanoudy H, Soliman A, Raggi P, Liu JW, Russell DC, Jarmukli NF. Prevalence of patent foramen ovale and its contribution to hypoxemia in patients with obstructive sleep apnea. Chest 1998;113(1):91-96.

3. Eisenmenger Syndrome. http://emedicine.medscape.com/ article/154555-overview. Accessed May 29, 2015.

4. Gatzoulis MA, Beghetti M, Landzberg MJ, Galiè N. Pulmonary arterial hypertension associated with congenital heart disease: recent advances and future directions. Int $J$ Cardiol 2014;177(2):340-347.

5. Daliento L. Eisenmenger syndrome. Factors relating to deterioration and death. Eur Heart J 1998;19(12):1845-1855. doi:10.1053/euhj.1998.1046.

6. Godart F, Rey C, Prat A, et al. Atrial right-to-left shunting causing severe hypoxaemia despite normal right-sided pressures. Report of 11 consecutive cases corrected by percutaneous closure. Eur Heart J. 2000;21(6):483-489. doi:10.1053/euhj.1999.1944.

7. Gladman DD, Urowitz MB. Venous syndromes and pulmonary embolism in systemic lupus erythematosus. Ann Rheum Dis 1980;39(4):340-343.

8. Chung W-S, Lin C-L, Chang S-N, Lu C-C, Kao C-H. Systemic lupus erythematosus increases the risks of deep vein thrombosis and pulmonary embolism: a nationwide cohort study. $J$ Thromb Haemost 2014;12(4):452-458. doi:10.1111/jth.12518.

9. Pego-Reigosa JM, Medeiros DA, Isenberg DA. Respiratory manifestations of systemic lupus erythematosus: old and new concepts. Best Pract Res Clin Rheumatol 2009;23(4):469-480. doi:10.1016/j.berh.2009.01.002.

10. Galiè N, Hoeper MM, Humbert M, et al. Guidelines for the diagnosis and treatment of pulmonary hypertension: the Task Force for the Diagnosis and Treatment of Pulmonary Hypertension of the European Society of Cardiology (ESC) and the European Respiratory Society (ERS), endorsed by the Internat. Eur Heart J 2009;30(20):2493-2537. doi:10.1093/eurheartj/ehp297.

11. Haddad RN, Mielniczuk LM. An Evidence-Based Approach to Screening and Diagnosis of Pulmonary Hypertension. Can J Cardiol 2015;31(4):382-390. doi:10.1016/j.cjca.2015.01.018.

12. Schreiber BE, Connolly MJ, Coghlan JG. Pulmonary hypertension in systemic lupus erythematosus. Best Pract Res Clin Rheumatol 2013;27(3):425-434. doi:10.1016/j.berh.2013.07.011. 13. Ruiz-Irastorza G, Garmendia M, Villar I, Egurbide M-V, Aguirre C. Pulmonary hypertension in systemic lupus erythematosus: prevalence, predictors and diagnostic strategy. Autoimmun Rev 2013;12(3):410-415. doi:10.1016/j.autrev.2012.07.010.
14. Dhala A. Pulmonary arterial hypertension in systemic lupus erythematosus: Current status and future direction. Clin Dev Immunol 2012;2012. doi:10.1155/2012/854941.

15. Magliano M, Isenberg DA, Hillson J. Pulmonary hypertension in autoimmune rheumatic diseases: where are we now? Arthritis Rheum 2002;46(8):1997-2009. doi:10.1002/art.10442.

16. Jais $X$, Launay D, Yaici A, et al. Immunosuppressive therapy in lupus- and mixed connective tissue disease-associated pulmonary arterial hypertension: a retrospective analysis of twentythree cases. Arthritis Rheum 2008;58(2):521-531. doi:10.1002/ art.23303.

17. Badesch DB, Hill NS, Burgess G, et al. Sildenafil for pulmonary arterial hypertension associated with connective tissue disease. J Rheumatol 2007;34(12):2417-2422.

18. Keogh AM, Jabbour A, Hayward CS, Macdonald PS. Clinical deterioration after sildenafil cessation in patients with pulmonary hypertension. Vasc Health Risk Manag 2008;4(5):1111-1113.

19. Bertoli AM, Vila LM, Apte M, et al. Systemic lupus erythematosus in a multiethnic US Cohort LUMINA XLVIII: factors predictive of pulmonary damage. Lupus 2007;16(6):410-417. doi:10.1177/0961203307079042.

20. Wijetunga M, Rockson S. Myocarditis in systemic lupus erythematosus. Am J Med 2002;113(5):419-423. doi:10.1016/ S0002-9343(02)01223-8.

21. Miner JJ, Kim AHJ. Cardiac manifestations of systemic lupus erythematosus. Rheum Dis Clin North Am 2014;40(1):51-60. doi:10.1016/j.rdc.2013.10.003.

22. Papiris SA, Manali ED, Kolilekas L, Triantafillidou C, Tsangaris I. Acute severe asthma: new approaches to assessment and treatment. Drugs. 2009;69(17):2363-2391. doi:10.2165/11319930-000000000-00000.

23. Lalloo UG, Ainslie GM, Abdool-Gaffar MS, et al. Guideline for the management of acute asthma in adults: 2013 update. $S$ Afr Med J 2013;103(3 Pt 2):189-198.

24. Hoffbrand BI, Beck ER. Unexplained dyspnoea and shrinking lungs in systemic lupus erythematosus. Br Med $\mathrm{J}$ 1965;1(5445):1273-1277.

25. Traynor AE, Corbridge TC, Eagan AE, et al. Prevalence and reversibility of pulmonary dysfunction in refractory systemic lupus: improvement correlates with disease remission following hematopoietic stem cell transplantation. Chest 2005;127(5):16801689. doi:10.1378/chest.127.5.1680.

26. Ye X, Feng Y, Lin S. Pulmonary embolism as the initial clinical presentation of Kimura disease: case report and literature review. Blood Coagul Fibrinolysis 2015;26(4):414-418. doi:10.1097/MBC.0000000000000278.

27. Calderaro DC, Ferreira GA. Presentation and prognosis of shrinking lung syndrome in systemic lupus erythematosus: report of four cases. Rheumatol Int 2012;32(5):1391-1396. doi:10.1007/ s00296-011-1863-5. 
28. Al-Raqum HA, Uppal SS, Al-Mutairy M, Kumari R. Shrinking lung syndrome as a presenting manifestation of systemic lupus erythematosus in a female Kuwaiti. Clin Rheumatol 2006;25(3):412-414. doi:10.1007/s10067-005-0020-5.

29. Karim MY, Miranda LC, Tench CM, et al. Presentation and prognosis of the shrinking lung syndrome in systemic lupus erythematosus. Semin Arthritis Rheum. 2002;31(5):289-298. 30.

30. Hardy K, Herry I, Attali V, Cadranel J, Similowski T. Bilateral phrenic paralysis in a patient with systemic lupus erythematosus. Chest 2001;119(4):1274-1277. http://www.ncbi.nlm.nih. gov/pubmed/11296200. Accessed May 16, 2015.

31. Toya SP, Tzelepis GE. Association of the Shrinking Lung Syndrome in Systemic Lupus Erythematosus with Pleurisy: A Systematic Review. Semin Arthritis Rheum 2009;39(1):30-37. doi:10.1016/j.semarthrit.2008.04.003.

32. Souza Neves F, da Silva THO, Paviani G, Fontes Zimmermann A, de Castro GRW, Alves Pereira I. Reinforcing a medical hypothesis with a new question: is there a subgroup of shrinking lungs syndrome that is induced by pleurisy in systemic lupus erythematosus and is this subgroup marked by anti-Ro/SSA? Clin Rheumatol 2010;29(7):777-779. doi:10.1007/s10067-0101427-1.

33. Oud KTM, Bresser P, ten Berge RJM, Jonkers RE. The shrinking lung syndrome in systemic lupus erythematosus: improvement with corticosteroid therapy. Lupus 2005;14(12):959963.

34. Peñacoba Toribio P, Córica Albani ME, Mayos Pérez M, Rodríguez de la Serna A. Rituximab in the treatment of shrinking lung syndrome in systemic lupus erythematosus. Reumatol Clin 10(5):325-327. doi:10.1016/j.reuma.2013.09.003.

35. Stankowski R V, Kloner RA, Rezkalla SH. Cardiovascular consequences of cocaine use. Trends Cardiovasc Med 2014. doi:10.1016/j.tcm.2014.12.013.

36. Pilgrim JL, Woodford N, Drummer OH. Cocaine in sudden and unexpected death: a review of 49 post-mortem cases. Forensic Sci Int 2013;227(1-3):52-59. doi:10.1016/j. forsciint.2012.08.037.

37. Leece P, Rajaram N, Woolhouse S, Millson M. Acute and chronic respiratory symptoms among primary care patients who smoke crack cocaine. J Urban Health 2013;90(3):542-551. doi:10.1007/s11524-012-9780-9.

38. Tseng W, Sutter ME, Albertson TE. Stimulants and the lung : review of literature. Clin Rev Allergy Immunol 2014;46(1):82100. doi:10.1007/s12016-013-8376-9.

39. Chin KM, Channick RN, Rubin LJ. Is methamphetamine use associated with idiopathic pulmonary arterial hypertension? Chest 2006;130(6):1657-1663. doi:10.1378/chest.130.6.1657.

40. Van Wolferen SA, Vonk Noordegraaf A, Boonstra A, Postmus PE. [Pulmonary arterial hypertension due to the use of amphetamines as drugs or doping]. Ned Tijdschr Geneeskd 2005;149(23):1283-1288. 